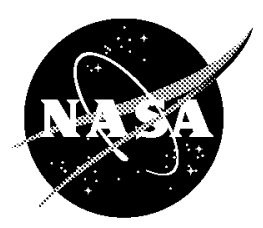

\title{
A Systems Model for Power Technology Assessment
}

David J. Hoffman

Glenn Research Center, Cleveland, Ohio 
The NASA STI Program Office ... in Profile

Since its founding, NASA has been dedicated to the advancement of aeronautics and space science. The NASA Scientific and Technical Information (STI) Program Office plays a key part in helping NASA maintain this important role.

The NASA STI Program Office is operated by Langley Research Center, the Lead Center for NASA's scientific and technical information. The NASA STI Program Office provides access to the NASA STI Database, the largest collection of aeronautical and space science STI in the world. The Program Office is also NASA's institutional mechanism for disseminating the results of its research and development activities. These results are published by NASA in the NASA STI Report Series, which includes the following report types:

- TECHNICAL PUBLICATION. Reports of completed research or a major significant phase of research that present the results of NASA programs and include extensive data or theoretical analysis. Includes compilations of significant scientific and technical data and information deemed to be of continuing reference value. NASA's counterpart of peerreviewed formal professional papers but has less stringent limitations on manuscript length and extent of graphic presentations.

- TECHNICAL MEMORANDUM. Scientific and technical findings that are preliminary or of specialized interest, e.g., quick release reports, working papers, and bibliographies that contain minimal annotation. Does not contain extensive analysis.

- CONTRACTOR REPORT. Scientific and technical findings by NASA-sponsored contractors and grantees.
- CONFERENCE PUBLICATION. Collected papers from scientific and technical conferences, symposia, seminars, or other meetings sponsored or cosponsored by NASA.

- SPECIAL PUBLICATION. Scientific, technical, or historical information from NASA programs, projects, and missions, often concerned with subjects having substantial public interest.

- TECHNICAL TRANSLATION. Englishlanguage translations of foreign scientific and technical material pertinent to NASA's mission.

Specialized services that complement the STI Program Office's diverse offerings include creating custom thesauri, building customized data bases, organizing and publishing research results... even providing videos.

For more information about the NASA STI Program Office, see the following:

- Access the NASA STI Program Home Page at http://wwo.sti.nasa.gov

- E-mail your question via the Internet to help@stinasa.gov

- Fax your question to the NASA Access Help Desk at 301-621-0134

- Telephone the NASA Access Help Desk at 301-621-0390

- Write to: NASA Access Help Desk NASA Center for AeroSpace Information 7121 Standard Drive Hanover, MD 21076 


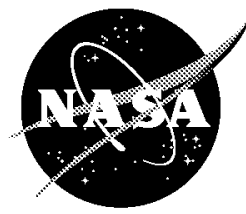

\section{A Systems Model for Power Technology Assessment}

David J. Hoffman

Glenn Research Center, Cleveland, Ohio

Prepared for the

37 th Intersociety Energy Conversion Engineering Conference sponsored by the Institute of Electrical and Electronics Engineers, Electron Devices Society

Washington, DC, July 28-August 2, 2002

National Aeronautics and

Space Administration

Glenn Research Center

July 2002 
Trade names or manufacturers' names are used in this report for identification only. This usage does not constitute an official endorsement, either expressed or implied, by the National Aeronautics and Space Administration.

Available from

NASA Center for Aerospace Information 7121 Standard Drive

Hanover, MD 21076
National Technical Information Service 5285 Port Royal Road Springfield, VA 22100

Available electronically at hito//gltrs.grc nasagov/GLTRS 


\title{
A SYSTEMS MODEL FOR POWER TECHNOLOGY ASSESSMENT
}

\author{
David J. Hoffman \\ National Aeronautics and Space Administration \\ Glenn Research Center \\ 21000 Brookpark Road \\ Cleveland, Ohio, 44135 \\ Phone: 216-433-2445 \\ Fax: 216-433-2995 \\ Email: david.j.hoffman@grc.nasa.gov
}

\begin{abstract}
A computer model is under continuing development at NASA Glenn Research Center that enables first-order assessments of space power technology. The model, an evolution of NASA Glenn's Array Design Assessment Model (ADAM), is an Excel workbook that consists of numerous spreadsheets containing power technology performance data and sizing algorithms. Underlying the model is a number of databases that contain default values for various power generation, energy storage and power management and distribution component parameters. These databases are actively maintained by a team of systems analysts so that they contain state-of-art data as well as the most recent technology performance projections. Sizing of the power subsystems can be accomplished either by using an assumed mass specific power $(\mathrm{W} / \mathrm{kg})$ or energy $(\mathrm{Wh} / \mathrm{kg})$ or by a bottoms-up calculation that accounts for individual component performance and masses. The power generation, energy storage and power management and distribution subsystems are sized for given mission requirements for a baseline case and up to three alternatives. This allows four different power systems to be sized and compared using consistent assumptions and sizing algorithms. The component sizing models contained in the workbook are modular so that they can be easily maintained and updated. All significant input values have default values loaded from the databases that can be over-written by the user. The default data and sizing algorithms for each of the power subsystems are described in some detail. The user interface and workbook navigational features are also discussed. Finally, an example study case that illustrates the model's capability is presented.
\end{abstract}

\section{IMPORTANCE OF SYSTEMS ANALYSIS}

System analysis provides the basis for sound technology program planning. The results of the tradeoff studies and technical assessments performed by systems analysts help provide the rationale to advocate and direct technology development programs. In the past, a successful case for developing new technology could be made by simply stating that it would cost less, weigh less or be more reliable than the baseline. Now, in order to justify the investment, technology program planners demand to know the magnitude of the technological benefit for specific missions or applications.

A well-planned, defendable technology development program needs accurate, consistent, unbiased "honest broker" technology assessments that temper the enthusiasm of advocates and fairly quantifies the benefits of competing technologies for specific missions and applications. It is also desirable to eliminate duplication and repetition in developing models and performing the systems analysis in order make the best use of human resources.

The power and on-board propulsion technology development program managers at NASA Glenn Research Center consider systems analysis to be extremely important and have formed a Systems Assessment Team to coordinate power and on-board propulsion systems analysis (Hoffman, 2000).

\section{ANALYSIS FIDELITY AND CONSISTENCY}

The fidelity and consistency of space power systems analysis results can vary widely for a number of reasons.

Regarding fidelity, there are top-level, first-order assessments that make high-level assumptions regarding technology performance, such as an assumed mass specific power $(\mathrm{W} / \mathrm{kg})$ or efficiency of a given subsystem, intended to quickly illuminate global trends and guide overall program planning. The feasibility of the assumed level of performance for the component or subsystem technology must then be substantiated, a point often either neglected or glossed over by "hand-waving." 
Alternatively, given more time and information, a more detailed "bottoms-up" analysis can be performed using higher-fidelity models to more accurately simulate the performance and/or determine the mass of a component or subsystem. The question in this case is whether or not the extra time and effort is worth the result. Ultimately, however, detailed highfidelity models are required in order to verify the performance initially estimated by the top-level systems analysis.

Regarding apparent inconsistencies, systems studies performed by different analysts can lead to apparently contradictory results because the analysts make slightly different assumptions for a number of parameters for different reasons, or use different criteria to assess the results. Analysis results can be further skewed if they are based on over optimistic predictions of the performance of newer, less mature technologies. Frequently, and for a variety of reasons, the actual performance of a newer technology in a specific application is much more conservative than initial optimistic expectations. In the end, simply understanding the motive of one organization or analyst performing the systems analysis versus another can go a long way in explaining their seemingly inconsistent results.

\section{BENEFITS OF A STANDARD MODEL}

Recognizing the issues associated with the varying levels of model fidelity and consistency, there is some appeal to developing a standard model, or set of models, to perform systems analysis. The kind of systems analysis that will be addressed for the remainder of this paper is that needed to be performed in a relatively quick fashion with a moderate degree of fidelity in order to discern meaningful trends in space power system technology performance in a subsystem, system or even spacecraft and mission-level context.

It is recognized that for this type of systems analysis, there are many competent engineers that could create spreadsheet level models to do the job. While each of their models may not violate the currently understood laws of physics, the level of fidelity in terms of the phenomena they choose to model and at what detail will not typically be the same. Also, it is a waste of an organization's human resources to have a new analyst create a new model for a similar study that was performed by a previous analyst who did not share their model and has since moved on.

For the efficient use of human resources and to ensure accuracy and consistency of analytical results, a standard model using consistent input parameters derived from a common database in a model that sizes space power systems with common algorithms which account for all relevant and significant phenomena that affects system performance and sizing is needed.

\section{MODELING APPROACH}

Because of their ease-of-use, ease-oftransmission (via email) and general ubiquity, spreadsheets are typically the software chosen for the top-level systems analysis models being discussed. NASA Glenn's initial approach at developing a model to assess solar arrays will be discussed next, followed by the continuing efforts to evolve the initial model into a standard space power system assessment tool.

\section{In the Beginning: ADAM}

In 1999, NASA Glenn contracted the development of an Excel ${ }^{T M}$ spreadsheet model with SAIC, Schaumburg, IL, that would enable a consistent comparison of solar array options using emerging thin-film solar cells versus those using traditional crystalline solar cells. While much less efficient at present, thin-film cells are much lighter $(\sim 4 x)$ than multijunction crystalline cells. Thin-film cells also hold the promise of being much cheaper to manufacture. The model sought by NASA Glenn would enable a consistent comparison of solar arrays in order to quantitatively determine the performance characteristics that the emerging thin-film cells must attain in order to be a viable option to the entrenched crystalline cell rigid array baseline most often flown in space. SAIC enlisted the support of Spectrum Astro, Gilbert, $A Z$, to create the model they dubbed ADAM, for Array Design Assessment Model. The ADAM model was first used in a thin-film array parametric assessment presented at the 2000 IECEC (Hoffman, et al., 2000).

\section{Then Came: EVE}

While ADAM performed well for its initial purpose of assessing solar arrays, it was incomplete from the perspective of assessing the performance of energy storage and power management and distribution technologies. Extending ADAM's approach to these other subsystems, a more comprehensive spacecraft power system assessment tool was created: EVE, or EValuation Engine.

EVE keeps the best features of ADAM and expands on them to enable comprehensive "bottomsup" assessment of not only solar array power generation, but also energy storage using a variety of chemical battery, regenerative fuel cell and flywheel energy storage technologies and more detailed power management and distribution components including solar array shunt regulators, battery charge/discharge units, power switching and distribution units and power distribution cables.

\section{MODEL DESCRIPTION}

EVE is a "top-down/bottoms-up" medium-fidelity Excel workbook that uses a structured approach to size a baseline solar photovoltaic space power system and three alternatives side-by-side for a given performance point. As such, it enables rapid, consistent comparisons of the impacts of space power technology at the system and spacecraft level. 
The phrase "top-down/bottoms-up" refers to the feature of the model that allows the analyst to simply assume the performance of power subsystems or components (e.g., specific power or energy, areal density and efficiency, etc.) when performing a "topsdown" analysis to quantify the system benefits in a "what-if" fashion. In "bottoms-up" mode, the analysts defines the mission requirements and selects component/technology types then lets the model's scaling algorithms calculate the component or subsystem performance.

Pertaining to EVE's fidelity, it is considered between high and low, hence medium, for the following reasons. For mass estimation, a high fidelity model would need to account for every component (or even piece-part) in a system and have accurate estimates or scaling rules for those components. For electric performance, a high-fidelity model would need to simulate the detailed electrical performance of components, subsystem and system as a function of time accounting for all significant environmental factors. At the opposite extreme, a low fidelity model may represent a power system only by its three main subsystems-power generation, energy storage and power management and distribution (PMAD) and simply assume top-level performance parameters and simple, linear scaling relationships.

EVE lies between these extremes, as will become apparent in the following sections.

\section{Model Organization and Configuration Control}

The EVE Excel workbook is a collection of 56 individual worksheets of six basic types: Configuration Control, Workbook Navigation, Database, Input Definition, Calculation, and Output/Results Display. Movement between the worksheets is facilitated by numerous macro buttons that use visual basic to rapidly change the active worksheet.

Within a worksheet, a cell's background and alphanumeric text is color coded to indicate whether it is a user-input (bold blue text/blue background), a default value resulting from a calculation (purple text/yellow background), an intermediate result (black text/light green background), or a calculation result used on another sheet (black text/bright green background). All input parameters have default values derived from database entries or calculations. These default values can be overridden in user-defined input cells for almost every input parameter. Pull-down menus are used wherever possible to present the user with a valid set of data selections. Named cells are used extensively to pass parameter values between worksheets efficiently.

On every input, calculation and output worksheet, the first column (Column A) contains the name or explanation of the parameters used in that sheet. The next column to the right (Column B) contains the values of those parameters for the Baseline power system option. The next three columns (Columns $C$, $D$ and $E$ ) contain the values for the three power system options being compared. These features increase the usability of the model not only for the model creators, but also for analysts unfamiliar with the model. All too often, the creator of a complex spreadsheet is the only one who can use it.

Because they are so easy to work with and transmit, spreadsheets can be difficult to place under configuration control. In the evolution of the ADAM, now EVE model, a deliberate attempt was made to keep track of changes and versions. The first worksheet in the EVE workbook is a "Change Control Log" to keep track of the version number of the model, a description of the latest changes and who made them, and the date and time. When the model is used for a specific analysis, the analysts are encouraged to keep the version number in the filename so as to easily indicate which version of the model was used when files are stored in a directory (e.g. the name of the Excel file used to illustrate this paper is IECEC02_EVE_V1p0.xls indicating EVE version 1.0 was used.)

\section{Main Navigation Worksheet}

The "Model Main Menu" worksheet should be the first sheet seen when opening the workbook, or at least the sheet to operate from when setting up an analysis. It contains links to every database, input, intermediate calculation and results output sheet. It is divided into four vertical and four horizontal sections. Horizontally, the top section looks like a block diagram of a space power system, as it is intended to be. Each block is actually a macro button that will take the user to the worksheet used to define a particular subsystem, such as solar arrays or energy storage. The next horizontal section contains macro buttons to take the user to the component parameter databases (e.g., solar cells). The third horizontal layer contains macro buttons to take the analyst to the intermediate calculation and component sizing worksheets. The bottom layer contains macro buttons to jump to the results display sheets.

The four vertical sections of the Main Menu sheet divide the four horizontal sections just described into Mission Definition, Solar Array, PMAD and Energy Storage areas.

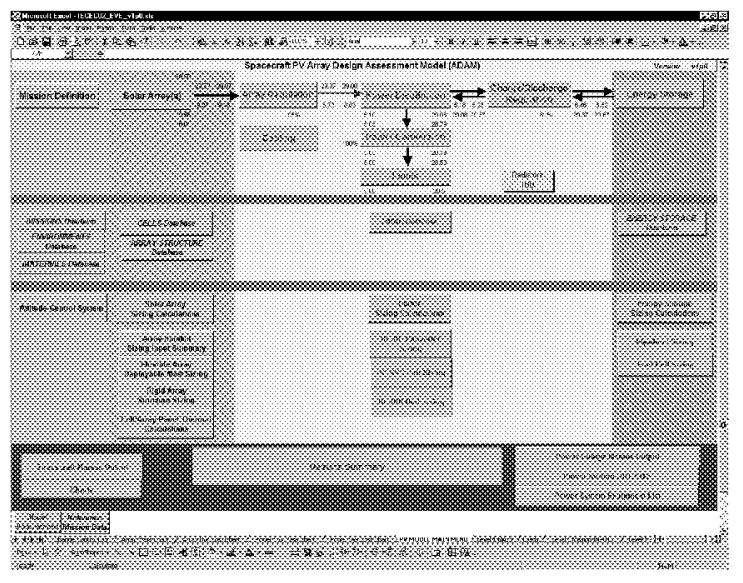

Figure 1 - Model Main Menu Worksheet 


\section{Databases}

There are seven databases contained in the workbook: Missions, Environments, Materials, Solar Cells, Array Structures, PMAD and Energy Storage. These databases store default values of all model input parameters.

The Missions database contains end-of-life (EOL) power requirements, mission duration, power subsystem and spacecraft description (mass, dimensions, etc.) defaults for six representative missions: LEO Earth Science, GEO Communications, Jupiter Orbiter, Near-Earth Deep Space (1.5 AU), Venus Orbiter, Mars Communication Orbiter.

The Environments database currently contains direct solar radiation, planetary infrared radiation, planetary radius, mass and average albedo values for Venus, Earth, the Moon, Mars and Jupiter.

The Materials database contains density, Poisson's ratio, Young's modulus, absorptivity and emmisivity data, as appropriate for the various materials that comprise solar cells, solar array support structures, and other space power system components.

The Solar Cells database contains beginning-oflife (BOL) cell efficiency at a user-defined reference temperature along with cell temperature coefficient and the material layers and thicknesses that comprise each solar cell listed in the database, among other data.

The Array Structures database contains data for sizing rigid honeycomb solar array panel substrates and representative areal density values for various flexible array support structures.

The PMAD and Energy Storage databases contain "top-down" specific power (W/kg), specific energy $(\mathrm{Wh} / \mathrm{kg})$ and efficiency data for various PMAD and energy storage technology options.

While the information in these databases can be edited, it is intended that the existing database entries would be left relatively static. New entries can easily be added to any of the databases so that the information can keep pace with technology development. If there is a need to override any of the default data loaded into the model from the databases, this can be done on the appropriate input worksheet, as described next.

\section{Input Worksheets}

There are six input worksheets: Mission Definition, Solar Arrays, PMAD, Cabling, Loads and Energy Storage. Default values for the input parameters defined on these sheets are fed by the databases just described or intermediate calculations performed on the sheet itself. So as not to destroy the database look-up formula that loads the default values, there is a separate cell where the user can enter values that the model will use instead of the defaults.

In the Mission Definition worksheet, the user must select the mission type and operating environment from a pull-down menu and define the mission lifetime in years. The default circular orbit altitude is based on the mission type selected, obtained from the Missions
Database. The user can define any altitude desired by entering a value in the "User-Defined Orbit Altitude" Cell. Calculated orbit period and maximum eclipse period for the central body selected by the mission type are given on this sheet as well.

Reflecting its heritage as an array design assessment model (ADAM), EVE's Solar Arrays input worksheet contains 43 user-defined parameters that fully describe a solar array from the bottom up: solar cell performance and material construction (material type and thickness for up to five layers), solar cell efficiency knockdown factors, solar array blanket or panel material construction (material type and thickness up to 3 layers), and solar array support structure type (rigid panel or flexible deployable) and characteristics (e.g., number of array wings, array wing aspect ratio, cell packing factor, rigid panel hinge stiffness or flexible array deployed first fundamental frequency).

\begin{tabular}{|c|c|}
\hline 101156x & 008010 \\
\hline (F) & (6ros \\
\hline 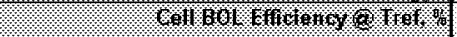 & $270 \%$ \\
\hline 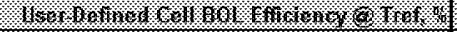 & \\
\hline 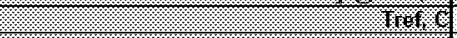 & 26 \\
\hline 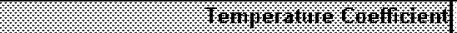 & 00022 \\
\hline 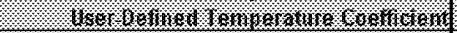 & \\
\hline (1) & 800 \\
\hline
\end{tabular}

Figure 2 - Solar Cell performance input data for Baseline case.

The PMAD input worksheet allows the user to define values for operating efficiency and specific power for four classes of components: Array Regulator Units, Battery Charge Regulator Units, Power Switching and Distribution Units, and DC-DC Converters. Efficiency and specific power values can be default values obtained from the PMAD Database, or a user-entered value. In the present version, the user can also use values calculated from more detailed "bottoms-up" sizing algorithms for the Power Switching and Distribution Unit and the DC-DC Converter Units. Detailed sizing models for the Array Regulation and Battery Charge Units have recently become available, but have not yet been integrated into the workbook.

\begin{tabular}{|c|c|}
\hline W & 9000 \\
\hline 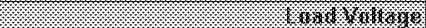 & 285 \\
\hline 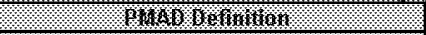 & Baseline \\
\hline 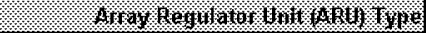 & 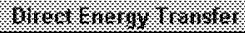 \\
\hline 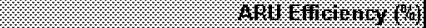 & $95 \%$ \\
\hline 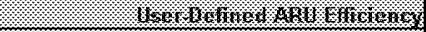 & \\
\hline 篗等 & 0105 \\
\hline 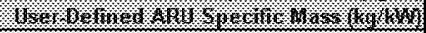 & \\
\hline 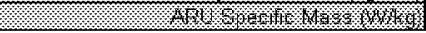 & 4 \\
\hline
\end{tabular}

Figure 3 - PMAD Array Regulation Unit input data for Baseline case.

There is a separate worksheet to calculate array wiring harness and power distribution cable masses based on user-defined cable transmission efficiency, 
cable lengths, conductor type ( $\mathrm{Al}$ or $\mathrm{Cu}$ ) and crosssection (flat or round), level of redundancy and iteratively-calculated cable operating temperature.

In the present version, the worksheet for defining the required load power consists of a cell to define the total required EOL power (W) and a cell to define the required load voltage. In future versions, the model could allow the definition of a distributed set of loads at user-defined voltages.

The Energy Storage input worksheet is similar to the PMAD input worksheet. It contains a table where the type of energy storage is selected from a pulldown menu displaying the technology options contained in the Energy Storage Database. Based on this selection, default values of roundtrip efficiency, maximum depth-of-discharge and specific energy are displayed. The user can then enter user-defined values for any of the parameters, if desired. The user can also select an option to have parameter values calculated from detailed "bottoms-up" worksheets for flywheels and regenerative fuel cells.

When using the calculated values for PMAD and energy storage devices, the user must go to those specific worksheets to further define a further set of input parameters.

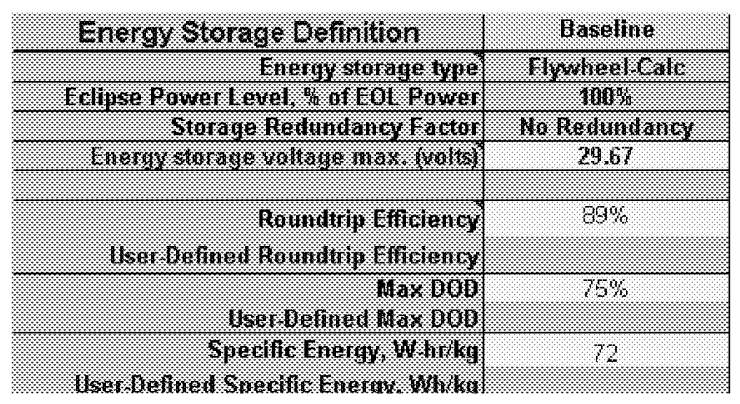

Figure 4 - Energy Storage input definition indicating calculated flywheel values have been selected.

\section{Calculation/Component Sizing Worksheets}

There are twelve intermediate calculation or component sizing worksheets that size the power subsystems to meet the mission requirements at $\mathrm{EOL}$ and calculate their corresponding masses, either with the tops-down user defined or defaulted specific power, energy and efficiency assumptions or with values for those parameters calculated by the more detailed bottoms-up component sizing algorithms, or a mixture of the two if so desired.

For the power generation subsystem, there is an overall Solar Array Sizing Calculation worksheet, a Flexible Array Deployment Mast Sizing sheet, a Rigid Array Structure Sizing sheet and a Cell/Array Panel Thermal Calculation sheet. The Flexible Array Deployment Mast Sizing sheet uses a curve of deployable lattice boom radius versus stiffness in order to size the array to meet a user-defined first fundamental deployed frequency requirement (for a more complete description, see Hoffman, et al., 2000). The Rigid Array Structure Sizing sheet also takes into account array stiffness requirements. The Cell/Array Panel Thermal Calculation sheet uses a single-node thermal model to estimate the cell operating temperature of a sun-tracking solar array at the sub-solar (orbit noon) point in a circular orbit about a central body.

For the PMAD subsystem, there is an overall PMAD Sizing Calculations sheet that calculates PMAD component masses sized to meet the mission requirements, either using top-down specific power and efficiencies or bottoms-up values calculated by the Array Regulation Unit, Battery Charge/Discharge Regulation Unit, DC-DC Converter Unit, and two types of Power Switching and Distribution Unit Sizing sheets.

Similarly for the Energy Storage subsystem, there is an overall Energy Storage Sizing Calculations sheet that calculates energy storage mass sized to meet the mission requirements using top-down specific energy and efficiencies. Alternatively, bottoms-up values calculated by Flywheel sizing or Fuel Cell Sizing sheets can be used. A bottoms-up chemical battery sizing sheet is planned.

In addition to the sheets dedicated to sizing and calculating the mass of the power system just described, there is an additional worksheet that estimates the effect of deployed solar arrays on the attitude control system. Specifically, the worksheet estimates the amount of propellant required for reboost due to atmospheric drag and desaturation of momentum wheels. This feature is extremely important when comparing the spacecraft-level mass impacts of larger-area lightweight thin-film arrays versus much smaller but heavier crystalline cell arrays. One such use of this feature in the ADAM model has been reported by Hoffman, et al. (2001).

\section{Main Results Summary Worksheet}

The main results summary worksheet contains seven sections of tabular data that allow rapid comparison of key input assumptions and output calculations: Mission Requirements \& Load Summary, System Design Summary, Power System Mass and Performance Summary, Array Performance Metrics, Solar Array Size Summary, Solar Array Mass Summary, and Array Structural Characteristics. These tables are illustrated in Figures 5 and 6.

There is also a worksheet that gives a detailed power subsystem mass breakdown and subsystem mass fractions.

\section{MODEL USAGE}

At this point, it should be evident that the EVE model greatly facilitates rapid definition, assessment and comparison of a baseline space power system and three alternatives (although only one alternate option is shown in the figures to save space). Although easy and quick to use in the hands of an experienced power systems analyst, the moderate fidelity of the model is aimed at allowing meaningful trends to be discerned that could be validated by higher-fidelity models. The model is ideally suited for 


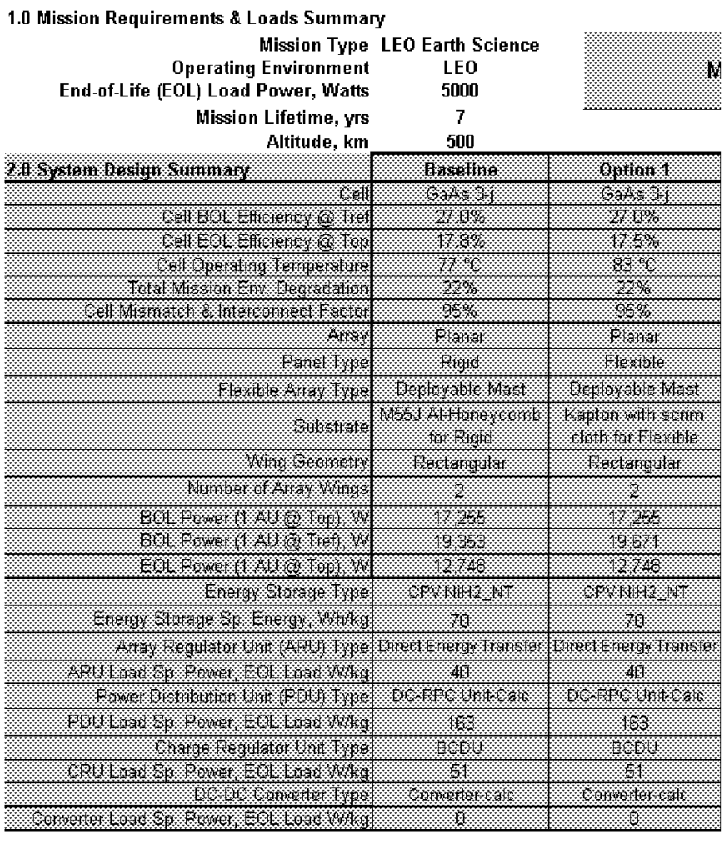

Figure 5 - Mission and System Design Input/Output Summary.

sensitivity studies to determine the systems-level effect of improvements in the technology of space power systems components, either singly, or in combination

While originally intended for use as a systems analysis tool to guide technology program planning the EVE model would also do well in a so-called "design center" environment where rapid conceptual system sizing is performed.

\section{PLANS}

Systems analysts at NASA Glenn plan to collaboratively evolve the EVE model (or whatever it ends up being called), adding increasing levels of fidelity and capability without compromising its easeof-use. The component databases will need to be updated to maintain pace with technology development. The bottoms-up component sizing models will be expanded and validated. Consideration will be given to adding time-dependent performance simulation, at least to some degree.

\section{CONCLUSION}

The comprehensive space power system sizing spreadsheet model described in this paper provides a standardized approach for performing systems analysis in order to quantify the impact of space power technology performance and discern meaningful trends to guide program planners.

\section{REFERENCES}

Hoffman, David J., 2000, "Power and On-Board Propulsion System Benefit Studies at NASA GRC,"
30 Power System Mass 2 Performance Summary

\begin{tabular}{|c|c|c|}
\hline \multirow{2}{*}{\multicolumn{3}{|c|}{ ? }} \\
\hline & & \\
\hline Poyer Systen Mass, kg & 832 & 717 \\
\hline Powe (Ceneration (4rays) kg & 267 & 152 \\
\hline Energ 8 torage, $\mathrm{kg}$ & 139 & 139 \\
\hline PMAD, $\mathrm{kg}$ & 078 & 370 \\
\hline cables, $\mathrm{kg}$ & 46 & 48 \\
\hline Power Sy stem BOL Top, $\$ / \mathrm{kg}$ & 21 & 24 \\
\hline Power S y sten Toulal Eficiency & $59 \%$ & $58 \%$ \\
\hline 40 Ariay Perlonmance hetrics & Baseline & Option 1 \\
\hline PV Elanket BOL Top, Wha & 130 & 268 \\
\hline Atra BOL Tod Wo SAEA, W/kg & 73 & 141 \\
\hline 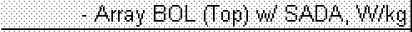 & 65 & 113 \\
\hline Subst, whe $8 \mathrm{trugt} \alpha \mathrm{Mech}, \mathrm{kg} / \mathrm{m}^{2}$ & 295 & 106 \\
\hline 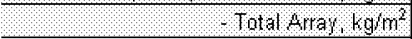 & 385 & 196 \\
\hline $\mathrm{BO}(\mathrm{Oop}) \mathrm{W} / \mathrm{m}^{2}$ & 280 & 275 \\
\hline 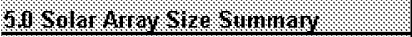 & Baseline & Qpion 1 \\
\hline 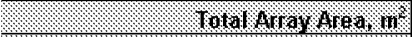 & 617 & 627 \\
\hline 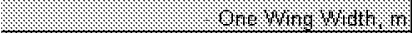 & 30 & 86 \\
\hline \%re & 180 & $7 \%$ \\
\hline 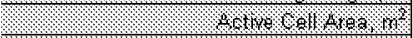 & $8 \%$ & $5 \%$ \\
\hline 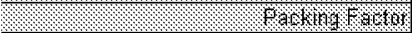 & 105 & 08 \\
\hline \multicolumn{3}{|l|}{ 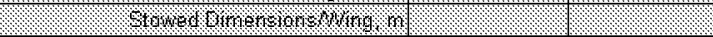 } \\
\hline 18096 & 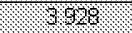 & 16 \\
\hline 16 & 8028 & 161 \\
\hline 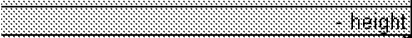 & 465 & 16 \\
\hline 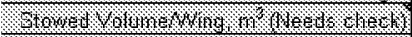 & 1652 & 105 \\
\hline $1 \% 1 \%$, & 18 & 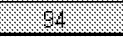 \\
\hline 60 Solar Array Mlass Summary & Baseline & Option 1 \\
\hline$\checkmark \checkmark$ Total Array Mass less SADA, kg & 237.7 & 122.7 \\
\hline Blanket with Substrate & 1832 & 64.4 \\
\hline Coverglas 1 Superstrate & 14.7 & 149 \\
\hline Cels & 408 & 415 \\
\hline Substrate & $77 \%$ & 61 \\
\hline Array Wling (calc) & 268 & 21 \\
\hline$\checkmark \checkmark, \checkmark, \checkmark,:, ~ Y o k e$ & 117 & 00 \\
\hline Clexible Array Support Structure & 01 & 60 \\
\hline Mechanisms & 660 & 245 \\
\hline SADA $1 / 5 \mathrm{~kg} / \mathrm{BO}$ BOL Top) & 290 & 295 \\
\hline Total Array has tnd SADA, kg & 2667 & 1522 \\
\hline 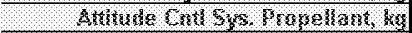 & 88 & 47 \\
\hline 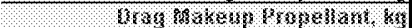 & 6 & 180 \\
\hline 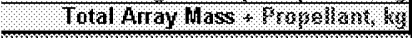 & 521 & 387 \\
\hline W & 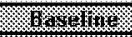 & 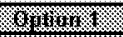 \\
\hline 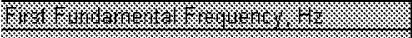 & $x$ & $x$ \\
\hline Ky: & 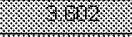 & 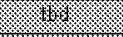 \\
\hline 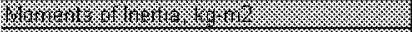 & \multicolumn{2}{|c|}{ 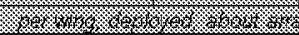 } \\
\hline & 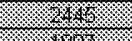 & 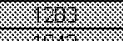 \\
\hline & $x$ & 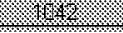 \\
\hline
\end{tabular}

Figure 6 - Power System Sizing Output Summary.

Proceedings, of the 2000 SAE Power Systems Conference, Society of Automotive Engineers, Warrendale, PA, pp. 173-178

Hoffman, et al., 2000, "Thin-Film Photovoltaic Solar Array Parametric Assessment," Proceedings, of the $35^{\text {th }}$ Intersociety Energy Conversion Engineering Conference, American Institute of Aeronautics and Aeronautics, pp. 670-680.

Hoffman, et al., 2001, "Thin-Film Solar Array Earth Orbit Mission Applicability Assessment", Space Photovoltaic Research and Technology Conference, NASA Glenn Research Center. 


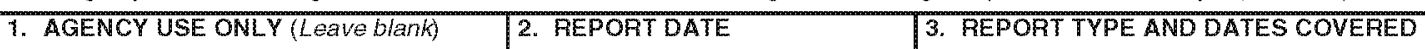

\begin{tabular}{|l|l|l|}
\hline & July 2002 & Technical Memorandum \\
\hline
\end{tabular}

\begin{tabular}{l|l} 
4. TITLE AND SUBTITLE & FUNDING NUMBERS
\end{tabular}

A Systems Model for Power Technology Assessment

6. AUTHOR(S)

WU-755-1A-16-00

David J. Hoffman

7. PERFORMING ORGANIZATION NAME(S) AND ADDRESS(ES)

National Aeronautics and Space Administration

John H. Glenn Research Center at Lewis Field

Cleveland, Ohio 44135-3191

9. SPONSORING/MONITORING AGENCY NAME(S) AND ADORESS(ES)

10. SPONSORING/MONITORING AGENCY REPORT NUMBER

National Aeronautics and Space Administration

Washington, DC 20546-0001

NASA TM-2002-211728

IECEC-2002-20038

\section{SUPPLEMENTARY NOTES}

Prepared for the 37th Intersociety Energy Conversion Engineering Conference sponsored by the Institute of Electrical and Electronics Engineers, Electron Devices Society, Washington, DC, July 28-August 2, 2002. Responsible person, David J. Hoffman, organization code 6920, 216-433-2445.

12a. DISTRIBUTION/AVAILABILITY STATEMENT 12b. DISTRIBUTION CODE

Unclassified-Unlimited

Subject Category: 20

Distribution: Nonstandard

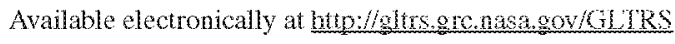

This publication is available from the NASA Center for AeroSpace Information, 301-621-0390.

13. ABSTRACT (Maximum 200 words)

A computer model is under continuing development at NASA Glemn Research Center that enables first-order assessments of space power technology. The model, an evolution of NASA Glenn's Array Design Assessment Model (ADAM), is an Excel workbook that consists of numerous spreadsheets containing power technology perfomance data and sizing algorithms. Underlying the model is a number of databases that contain default values for various power generation, energy storage and power management and distribution component parameters. These databases are actively maintained by a team of systems analysts so that they contain state-of-art data as well as the most recent technology performance projections. Sizing of the power subsystems can be accomplished either by using an assumed mass specific power ( $/ \mathrm{kg}$ ) or energy ( $\mathrm{Wh} / \mathrm{kg}$ ) or by a bottoms-up calculation that accounts for individual component performance and masses. The power generation, energy storage and power management and distribution subsystems are sized for given mission requirements for a baseline case and up to three alternatives. This allows four different power systems to be sized and compared using consistent assumptions and sizing algorithms. The component sizing models contained in the workbook are modular so that they can be easily maintained and updated. All significant input values have default values loaded from the databases that can be over-written by the user. The default data and sizing algorithms for each of the power subsystems are described in some detail. The user interface and workbook navigational features are also discussed. Finally, an example study case that illustrates the model's capability is presented.

14. SUBJECT TERMS

Computer programs; Spreadsheets; Spacecraft models; Spacecraft power supplies; Electric power

\begin{tabular}{|c|c|c|c|}
\hline $\begin{array}{c}\text { 17. SECURITY CLASSIFICATION } \\
\text { OF REPORT } \\
\text { Unclassified }\end{array}$ & $\begin{array}{c}\text { 18. SECURITY CLASSIFICATION } \\
\text { OF THIS PAGE } \\
\text { Unclassified }\end{array}$ & $\begin{array}{c}\text { 19. SECURITY CLASSIFICATION } \\
\text { OF ABSTRACT } \\
\text { Unclassified }\end{array}$ \\
\hline
\end{tabular}

NSN 7540-01-280-5500 